DOI: 10.20472/IAC.2018.935.043

IRINA SIDORCUKA

RISEBA University of Business, Arts and Technology, Latvia

\title{
MULTIDISCIPLINARY PROJECT IN BUSINESS EDUCATION
}

\begin{abstract}
:
Art -based teaching and learning have already become a recognized instrument in educational programmes applied in a variety of forms. The primary goal of this research was to examine contemporary visual art as a learning environment and analyse the effect it can bring in the teaching -learning process and outcomes in contemporary business education .

The article shares experience gained through combining several courses with multiple teaching aims thus creating an integrated project environment for the students in order to foster their learning outcomes through enrichment of teaching-learning methods and increased motivation. The project was carried out in the framework of the hybrid lectures course "Business Meets Art" combining English for Professional Purposes( Business), Personal Development and Study Skills and Presentation Skills courses.

The observation and quantitative analysis were applied, combining students self-evaluation and academic staff assessment of the effects produced by the project followed by interview and discussion.

The experiment of using visual art as a learning environment in multidisciplinary teaching demonstarated a huge potential of this form of work in higher business education providing development of both linguistic skilss ( reading, writing, listening, speaking skills), combined with advancement of personal development ( critical thinking, emotional intelligence, creativity, artistic skills, communicative and leadership skills, teamwork, cross-cultural interaction, responsibility, active citizenship, etc.) , and professional business skill such as entrepreneurship, marketing and advertising, negotiating, leadership. The effect of multidisciplinary was highly appreciated both by the students and the academic staff and had a powerful impact on motivation with a long-term influence over the participants, unlocking students talents, fostering self-development and self-actualization required in the contemporary education.
\end{abstract}

\section{Keywords:}

visual art, multidisciplinary education, personal development, motivation, art-based teaching-learning

JEL Classification: $123, A 12, A 12$ 